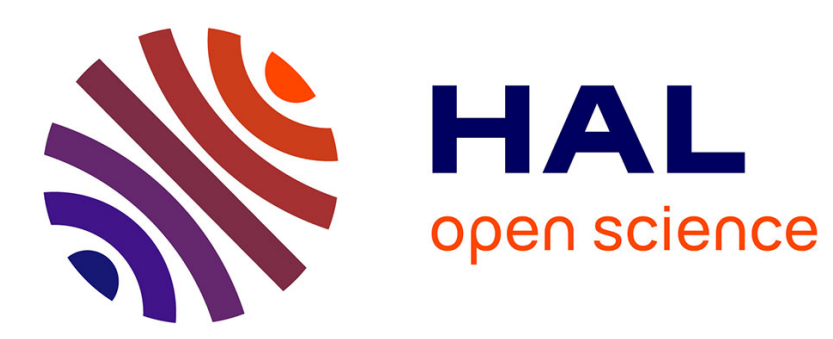

\title{
Ideal concentrators with polygonal absorbers
}

\author{
F. Bloisi, L. Vicari, D. Ruggi, F. Suraci
}

\section{To cite this version:}

F. Bloisi, L. Vicari, D. Ruggi, F. Suraci. Ideal concentrators with polygonal absorbers. Revue de Physique Appliquée, 1986, 21 (2), pp.163-167. 10.1051/rphysap:01986002102016300 . jpa-00245421

\section{HAL Id: jpa-00245421 https://hal.science/jpa-00245421}

Submitted on 1 Jan 1986

HAL is a multi-disciplinary open access archive for the deposit and dissemination of scientific research documents, whether they are published or not. The documents may come from teaching and research institutions in France or abroad, or from public or private research centers.
L'archive ouverte pluridisciplinaire HAL, est destinée au dépôt et à la diffusion de documents scientifiques de niveau recherche, publiés ou non, émanant des établissements d'enseignement et de recherche français ou étrangers, des laboratoires publics ou privés. 
Classification

Physics Abstracts

$42.78-42.80-86.30 \mathrm{R}$

\title{
Ideal concentrators with polygonal absorbers $\left({ }^{*}\right)$
}

\author{
F. Bloisi, L. Vicari \\ Dipartimento di Fisica Nucleare, Struttura della Materia e Fisica Applicata, \\ Facoltà di Ingegneria, Università di Napoli, 80125 Napoli, Italy \\ D. Ruggi
}

A.P.R.E. S.p.A., Roma, Italy

and F. Suraci

E.N.E.A.-F.A.R.E., Roma, Italy

(Reçu le 27 juillet 1984, révisé le 8 juillet 1985, accepté le 8 novembre 1985)

\begin{abstract}
Résumé. - Nous avons introduit une nouvelle famille de concentrateurs stationnaires symétriques idéaux avec des absorbeurs poligonaux. Nous avons étudié en quelques détails leurs caractéristiques géométriques et nous avons montré que quelques-uns d'entre eux sont particulièrement aptes à se ranger dans des panneaux plans, et d'autres sont utiles lorsque l'isolement thermique est obtenu en insérant l'absorbeur dans un tube de verre sous vide.
\end{abstract}

\begin{abstract}
We introduce a new family of ideal symmetrical stationary concentrators with absorbers having a polygonal cross section. We study in some detail their geometrical features and show that some of them are particularly well suited to be arranged in flat panels, while others are useful when the thermal insulation is obtained inserting the receiver into an evacuated glass pipe.
\end{abstract}

\section{Nomenclature}

C Concentration factor

$C^{*}$ Concentration factor for an ideal device

$d$ Collector semiaperture (half of the entrance aperture width)

$d^{\prime} \quad$ Absorber semiperimeter

$h \quad$ Maximum depth of the device

$\theta_{\mathbf{M}}$ Semiacceptance angle (half of the angular field of view)

\section{Introduction.}

Since the first studies of Winston [1 to 3] and Baranov [4 to 6] on the Compound Parabolic Concentrator (CPC) many authors have dealt with the matter of new shapes for ideal concentrators [7 to 12].

$\left(^{*}\right)$ Financially supported by E.N.E.A.-F.A.R.E.
An ideal cylindrical concentrator is a device able to collect radiation over an entrance aperture of width $2 d$, an angular field of view of $2 \theta_{\mathrm{M}}$ in the plane traverse to the cylindre and to concentrate all of it on an absorber of width $2 d^{\prime}$. The concentration factor $C^{*}=d / d^{\prime}$ is given by

$$
C^{*}=1 / \sin \theta_{\mathrm{M}} .
$$

Ideal concentrators are often used to realize actual devices aimed to the collection of solar energy. In this case one has to consider other parameters besides the concentration factor, like the shape of the absorber when it has to be inserted into an evacuated glass tube or the depth of the mirror when it has to be assembled into a concentrating flat plate configuration.

In their paper [7] Winston and Hinterberger, developing an idea of Trombe and Meinel [8], introduced the cylindrical concentrator with absorbers of very general cross section. They dealth in more detail with circular, oval and fin absorbers. An example is given in figure 1a (Type 1 : circular absorber).

These concentrators use the whole surface of the 

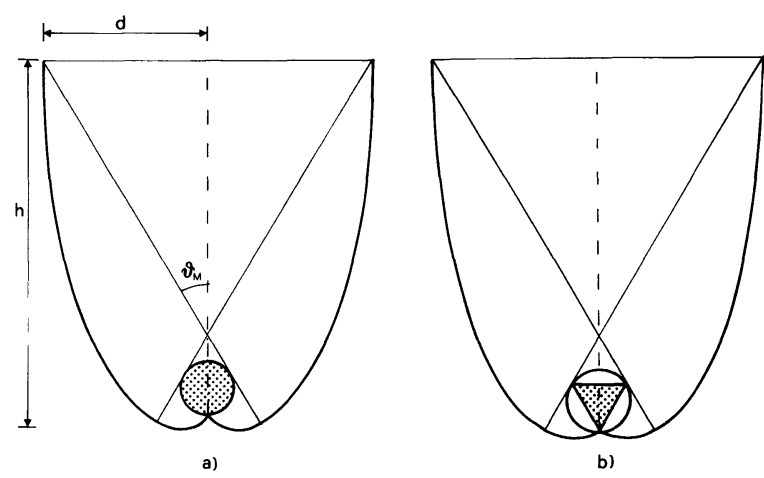

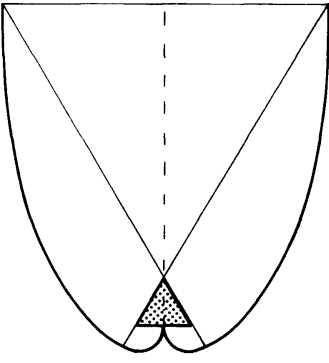

c)

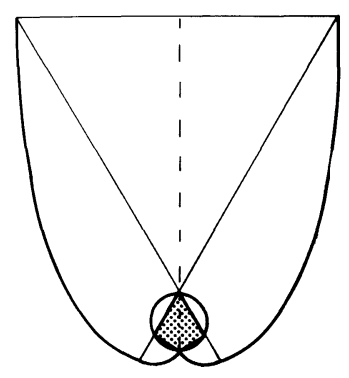

d)
Fig. 1. - Different concentrator types : a) Type 1 : circular absorber, b) Type 2 : triangular absorber, c) Type 3 : «delta " absorber, d) Type 4 : inscriptable quadrilateral absorber.

absorber as receiver while in a CPC only half of it is useful. Besides that the thermal insulation of the receiver can be achieved by means of its insertion into an evacuated glass tube.

Nevertheless, as it was observed by McIntire [11], in actual cases this arrangement implies high optical losses (Fig. 2a). McIntire proposed a very elegant solution of this problem : the solution was based on a W shape of the mirror underneath the receiver(Fig. 2b). While geometrically perfect, this approach can produce some difficulties and therefore, it increases the manufacturing costs. Besides that, in an actual mirror, optical losses are reduced, but not eliminated, since the W shape requires more reflections than the original one.

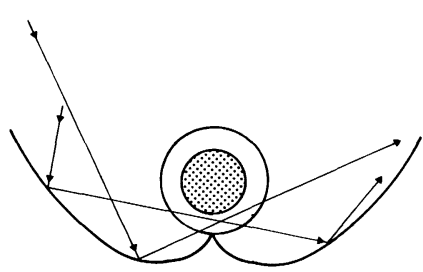

a)

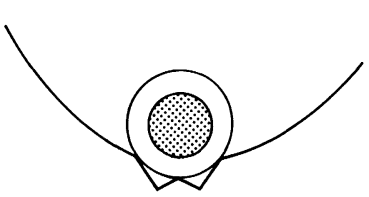

b)
Fig. 2. - Reduction of optical losses with the non-imaging cusp reflector by McIntire.
In the light of these considerations, we shall here discuss the properties and the advantages of a family of ideal concentrators with polygonal absorbers.

\section{Triangular receivers.}

We will consider first the solution shown in figure $1 b$ (Type $2:$ triangular absorber). The proposed receiver has the advantage of being simpler and less expensive then the type 1 (Fig. 1a) or McIntire's (Fig. 2b), while it eliminates the optical losses through the gap between the absorber and the mirror, without increasing the number of reflections.

Let us show how a such concentrator is realized. The triangle $\mathrm{ABC}$ (Fig. 3) is equilateral; the extreme rays are $\mathrm{PB}^{\prime}$ and $\mathrm{D}^{\prime} \mathrm{C}$. The arc $\mathrm{AB}^{\prime}$ belongs to the circle with centre $\mathrm{B}$ and radius $s=\mathrm{AB} ; \mathrm{B}^{\prime}$ is the intersection between this circle and the extreme ray $\mathrm{PB}$. This arc is the involute of the absorber. The $\operatorname{arc} \mathrm{B}^{\prime} \mathrm{C}^{\prime}$ belongs to the parabola with axis parallel to $\mathrm{PB}$ and focus $\mathrm{B}$ where $\mathrm{C}^{\prime}$ is the intersection with the stright line through CB. The arc $C^{\prime} D^{\prime}$ belongs to the parabola with axis parallel to $\mathrm{PB}$ and focus in $\mathrm{C}$, and $\mathrm{D}^{\prime}$ is the intersection with the extreme ray $\mathrm{D}^{\prime} \mathrm{C}$. The tangent to this parabola in $\mathrm{D}^{\prime}$ is parallel to the optical axis $\mathrm{OA}$; in fact, a ray arriving in $\mathrm{D}^{\prime}$ along the direction of the extreme ray $\mathrm{PB}^{\prime}$ is reflected in $\mathrm{C}$.

We give now (Fig. 3) a Cartesian representation of

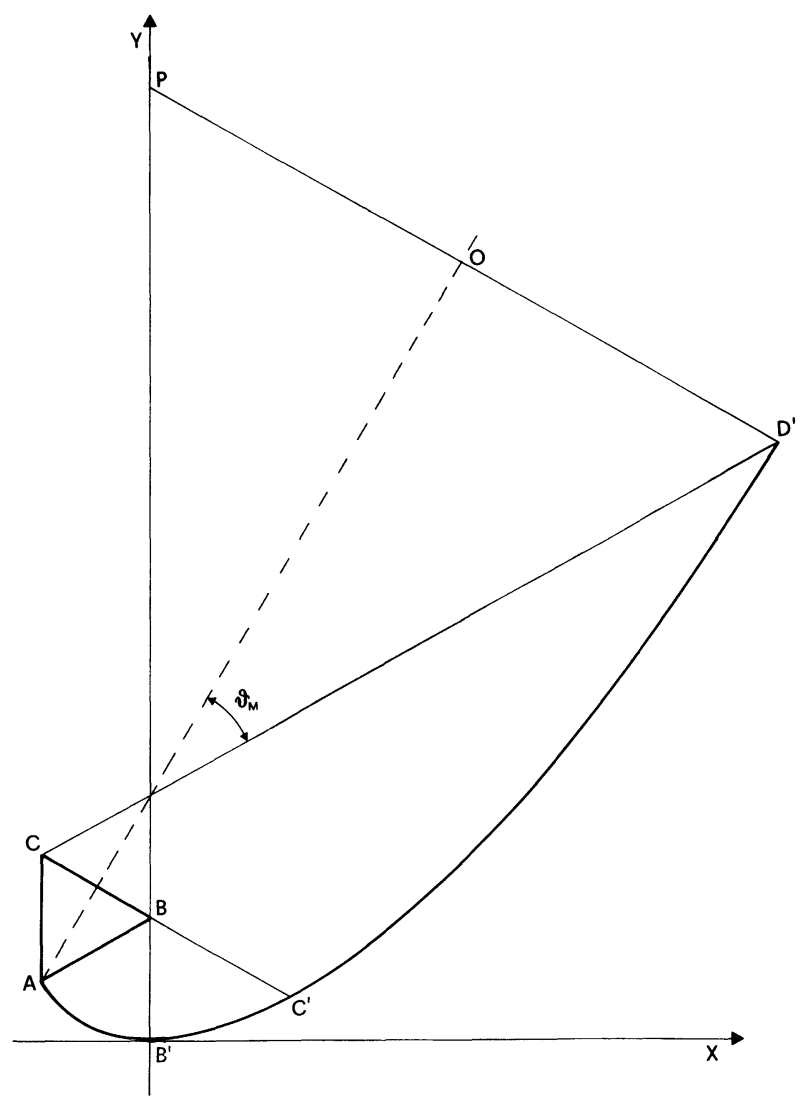

Fig. 3. - Construction of a type 2 concentrator. 
the right hand side of the concentrator; the left side can be obtained by symmetry.

The equation of the reflector, between $\mathrm{A} \equiv\left(x_{\mathrm{A}}, y_{\mathrm{A}}\right)$ and $\mathbf{B}^{\prime} \equiv\left(x_{\mathbf{B}^{\prime}}, y_{\mathbf{B}^{\prime}}\right)$, is

$$
x^{2}=y(2 s-y)
$$

with

$$
\begin{gathered}
x_{\mathbf{A}}=\left(\sqrt{3} \sin \theta_{\mathbf{M}}+\cos \theta_{\mathbf{M}}\right) s / 2 \\
y_{\mathbf{A}}=\left(2-\sqrt{3} \cos \theta_{M}+\sin \theta_{M}\right) s / 2 \\
x_{\mathbf{B}^{\prime}}=y_{\mathbf{B}^{\prime}}=0 .
\end{gathered}
$$

Between $\mathbf{B}^{\prime}$ and $\mathbf{C}^{\prime} \equiv\left(x_{\mathbf{C}^{\prime}}, y_{\mathbf{C}^{\prime}}\right)$ the equation is

$$
x^{2}=4 s y
$$

with

$$
\begin{aligned}
& x_{\mathbf{C}^{\prime}}=2 s\left(1-\sin \theta_{\mathbf{M}}\right) / \cos \theta_{\mathbf{M}} \\
& y_{\mathbf{C}^{\prime}}=s-x_{\mathbf{C}^{\prime}} \tan \theta_{\mathbf{M}} .
\end{aligned}
$$

Between $C^{\prime}$ and $D^{\prime} \equiv\left(x_{D^{\prime}}, y_{D^{\prime}}\right)$ the equation is

$$
y=a x^{2}+b x+c
$$

where

$$
\begin{aligned}
& a=\left(y_{F}-2 s\right) / 2 \\
& b=-x_{F} /\left(y_{F}+2 s\right) \\
& c=\frac{x_{F}^{2}+y_{F}^{2}-4 s^{2}}{2\left(y_{F}+2 s\right)}
\end{aligned}
$$

and $x_{\mathrm{F}}$ and $y_{\mathrm{F}}$ are the coordinates of the focus $\mathrm{C}$, given by

$$
\begin{aligned}
& x_{\mathrm{F}}=-s \cos \theta_{\mathrm{M}} \\
& y_{\mathrm{F}}=s\left(1+\sin \theta_{\mathrm{M}}\right) .
\end{aligned}
$$

To evaluate the coordinates of $\mathrm{D}^{\prime}$ we remember that the tangent to the parabola in $D^{\prime}$ is parallel to the axis OA, so

$$
\left.\frac{\mathrm{d} y}{\mathrm{~d} x}\right|_{\boldsymbol{x}_{=\mathbf{D}_{\mathbf{D}^{\prime}}}}=2 a x_{\mathbf{D}^{\prime}}+b=\operatorname{cotg} \theta_{\mathbf{M}}
$$

therefore

$$
x_{\mathbf{D}^{\prime}}=3 s \cos \theta_{\mathbf{M}} / \sin \theta_{\mathbf{M}} \text {. }
$$

To show that the concentrator is ideal we evaluate the concentration factor

$$
C=d / d^{\prime}=2 \mathrm{OD}^{\prime} / 3 s
$$

and verify that it equals the ideal concentration factor $C^{*}$. In fact, from geometrical consideration we get

$$
2 \mathrm{OD}^{\prime}=x_{\mathrm{D}^{\prime}} / \cos \theta_{\mathrm{M}}=3 \mathrm{~s} / \sin \theta_{\mathrm{M}}
$$

so that

$$
C=1 / \sin \theta_{\mathrm{M}}=C^{*} \text {. }
$$

\section{Quadrilateral receivers.}

Optical losses are very important for actual applications. Nevertheless further improvement can be obtain- ed reducing the volume occupied by the devices. An ideal concentrator has, for unit absorber area, a given width, but it can have different depth.

We take into account now a geometrical family of devices which shows some advantages from this point of view.

Let us consider figure $4: \theta_{M}$ is the semiacceptance angle of the concentrator, $\mathrm{OC}$ is the optical axis, PC and $\mathrm{D}^{\prime} \mathrm{C}$ are the extreme rays. We arbitrarily chose the point B on PC. Let it be $d^{\prime}=\mathrm{CB}$.

For each point $L$ on the segment $C B$, let $A$ be the lower of the two points of the optical axis whose distance from $\mathrm{L}$ is $\mathrm{LB}$, which exists under the condition

$$
\mathrm{LB} \geqslant \mathrm{CL} \sin \theta_{\mathrm{M}}
$$

or equivalently

$$
\mathrm{AL} \geqslant\left(d^{\prime} \sin \theta_{\mathrm{M}}\right) /\left(1+\sin _{u} \theta_{\mathbf{M}}\right) .
$$

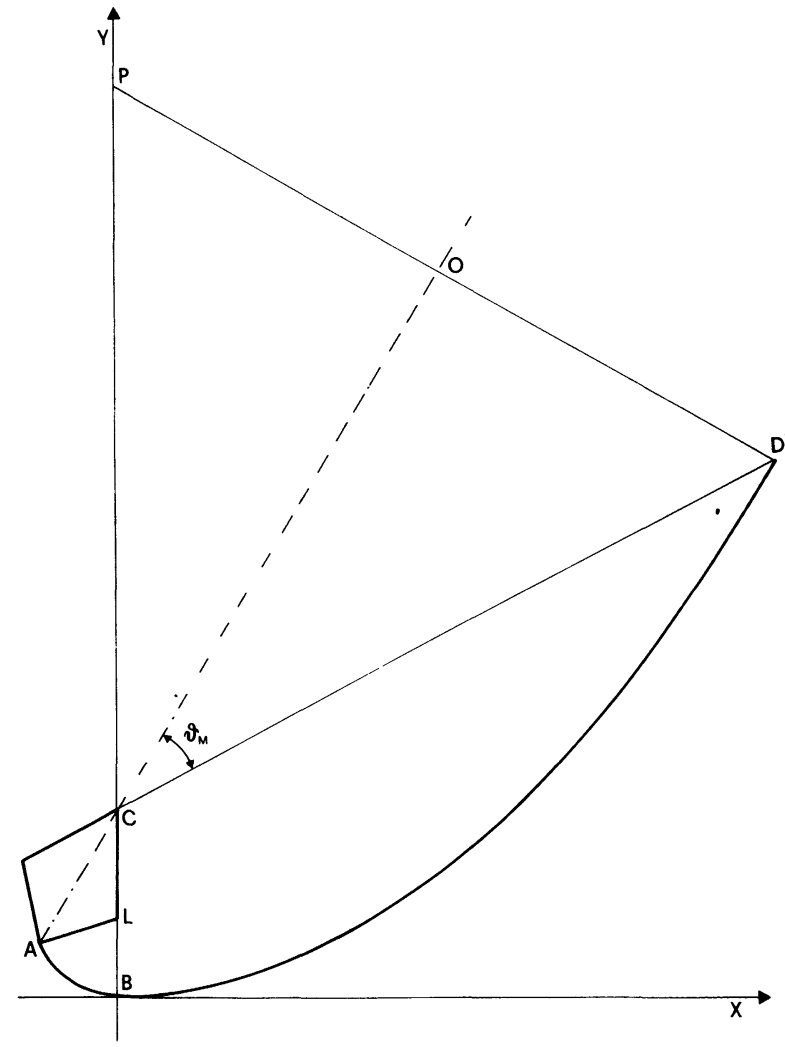

Fig. 4. - Construction of a concentrator with polygonal receiver.

Again, we describe the right hand side of the device. CLA is the cross section of the receiver. The arc $A B$ of the mirror belongs to the circumference with centre in $L$ and radius $L B=L A$. The arc $B^{\prime}$ of the mirror belongs to the parabola with axis $\mathrm{PC}$ and focus in $\mathrm{C}$; $\mathrm{D}^{\prime}$ is the intersection with the extreme ray $\mathrm{BD}^{\prime}$, or equivalently the point where the tangent to the parabola has the direction of the optical axis. 


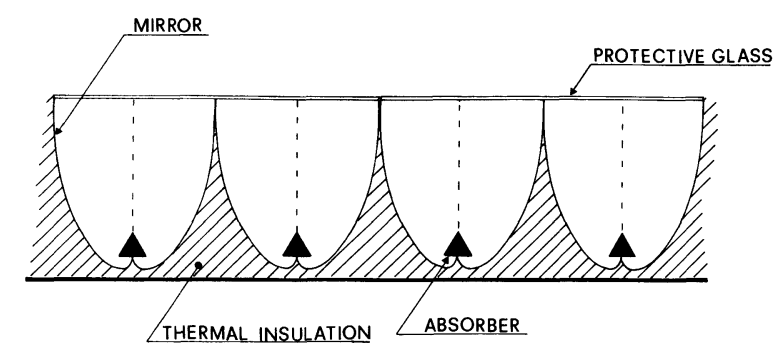

Fig. 5. - Concentrators assembled in a flat panel configuration.

For the Cartesian representation of the concentrator let us look at figure 4. The equation of the $\operatorname{arc} A B$ is that of a circumference and depends on the choice for $L$. The arc $\mathbf{B D}^{\prime}$ has equation

$$
x^{2}=4 y d^{\prime} .
$$

If we look for the point $\mathrm{D}^{\prime} \equiv\left(x_{\mathrm{D}^{\prime}}, y_{\mathrm{D}^{\prime}}\right)$, as previously done, we find :

$$
x_{\mathbf{D}^{\prime}}=2 d^{\prime} / \tan \theta_{\mathbf{M}} \quad y_{\mathbf{D}^{\prime}}=d^{\prime} / \tan ^{2} \theta_{\mathbf{M}} .
$$
also

From geometrical considerations on figure 6 we get

$$
2 \mathrm{OD}^{\prime}=x_{\mathbf{D}^{\prime}} / \cos \theta_{\mathrm{M}}=2 d^{\prime} / \sin \theta_{\mathrm{M}} .
$$

The concentration factor is then given by :

$$
C=d / d^{\prime}=\mathrm{OD}^{\prime} / d^{\prime}=1 / \sin \theta_{\mathrm{M}}=C^{*}
$$

and therefore each concentrator obtained in this way is ideal.

The depth $h$ of the concentrators of this family is given by

$h=d \operatorname{ctan} \theta_{\mathrm{M}}+\mathrm{AL}\left(1-\cos \theta_{\mathrm{M}}\right)+d \sin \theta_{\mathrm{M}} \cos \theta_{\mathrm{M}}$

and, for given semiaperture $d$ and semiacceptance angle $\theta_{\mathrm{M}}$, depends on the choice for the point $\mathrm{L}$. The value of AL which minimize the device's depth is given by the existence condition of $\mathrm{L}$ mentioned above. In this case the triangle CAL is rectangular in A, the receiver is a triangle, and we can write

$$
\begin{aligned}
& \mathrm{AL}=d \sin ^{2} \theta_{\mathrm{M}} /\left(1+\sin \theta_{\mathrm{M}}\right) \\
& \mathrm{CL}=d \sin \theta_{\mathrm{M}} /\left(1+\sin \theta_{\mathrm{M}}\right) .
\end{aligned}
$$

The resulting concentrator is shown in figure 1c (Type 3 : delta absorber).

Such a concentrator can be very useful for applications in flat panels with external cover glass. Nevertheless, just like the concentrator with circular receiver, it is useless if the insulation is obtained by means of cylindrical vacuum pipe.

In figure $1 \mathrm{~d}$ we show a device (Type 4 : inscriptable quadrilateral absorber) which has both the advantages of small depth and negligible optical losses. Its receiver is obtained as before, but now the triangle CLA is rectangular in $\mathrm{L}$. The resulting absorber is a quadri- later inscriptable in a circumference. In this case we have

$$
\begin{aligned}
& \mathrm{AL}=d \sin ^{2} \theta_{\mathrm{M}} /\left(\sin \theta_{\mathrm{M}}+\cos \theta_{\mathrm{M}}\right) \\
& \mathrm{CL}=d \sin \theta_{\mathrm{M}} \cos \theta_{\mathrm{M}} /\left(\sin \theta_{\mathrm{M}}+\cos \theta_{\mathrm{M}}\right) .
\end{aligned}
$$

\section{Conclusions.}

There are two main ways to assemble the solar concentrators for heating purposes.

In the first case (flat panels, Fig. 5), many concentrators are inserted into a box; the top is closed by a single or double glass and the bottom is thermally insulated.

In the second case (Fig. 1d), as mentioned above, the thermal insulation is obtained by inserting the receiver into an evacuated glass pipe.

We discussed here five different geometries of concentrators. All of them may be used in the flat panel configuration while only the types 2 and 4 may be used for glass pipes. The use of the types 1 and 3 in this configuration imply an arbitrary cut of the mirror or an arbitrary shift of the receiver, or both, resulting in a non ideal concentrator with a lot of optical losses, the amount of which depends on the shape of the actual device.

In both configurations all of the types 1,2,3 and 4 are equivalent with respect to the problem of the thermal insulation. Only the CPC has the disadvantage of a thermal wasting area which is twice the absorbing one ; furthermore half of it is in direct contact with the bottom of the box.

Table I. - Depth to semiaperture ratio versus the semi-acceptance angle.

\begin{tabular}{|c|c|c|c|c|c|}
\hline \multirow{2}{*}{$\begin{array}{c}\text { Semi } \\
\text { accep- } \\
\text { tance }\end{array}$} & \multicolumn{5}{|c|}{ Depth/semiaperture $h / d$} \\
\cline { 2 - 6 }$\theta_{\mathrm{M}}$ & CPC & Type 1 & Type 2 & Type 3 & Type 4 \\
\hline $0^{\circ}$ & $\infty$ & $\infty$ & $\infty$ & $\infty$ & $\infty$ \\
$10^{\circ}$ & 6.537 & 6.076 & 6.115 & 5.843 & 5.843 \\
$20^{\circ}$ & 3.687 & 3.237 & 3.289 & 3.074 & 3.074 \\
$30^{\circ}$ & 2.598 & 2.300 & 2.354 & 2.187 & 2.190 \\
$40^{\circ}$ & 1.958 & 1.831 & 1.876 & 1.743 & 1.753 \\
$50^{\circ}$ & 1.482 & 1.540 & 1.564 & 1.450 & 1.480 \\
$60^{\circ}$ & 1.077 & 1.329 & 1.321 & 1.211 & 1.285 \\
$70^{\circ}$ & 0.706 & 1.152 & 1.104 & 0.985 & 1.139 \\
$80^{\circ}$ & 0.350 & 0.987 & 0.891 & 0.751 & 1.039 \\
$90^{\circ}$ & 0.000 & 0.818 & 0.667 & 0.500 & 1.000 \\
\hline
\end{tabular}

In the following we show the expressions of the ratio between the depth and the semiaperture for all the types of concentrators (see Table I) : 
CPC $: h / d=\operatorname{cotg} \theta_{\mathrm{M}}+\cos \theta_{\mathrm{M}}$

Type $1: h / d=\operatorname{cotg} \theta_{\mathrm{M}}+1 / \pi+\left(\sin \theta_{\mathrm{M}}\right) / 2$

Type $2: h / d=\operatorname{cotg} \theta_{M}+\left(\cos \theta_{M}+2 \sin \theta_{M}\right) / 3$

Type $3: h / d=\operatorname{cotg} \theta_{\mathrm{M}}+$ $+\sin \theta_{M}\left(\sin \theta_{M}+\cos \theta_{M}\right) /\left(1+\sin \theta_{M}\right)$

Type $4: h / d=c \tan \theta_{M}+$

$+\left(\sin ^{2} \theta_{M}+\sin \theta_{M} \cos ^{2} \theta_{M}\right) /\left(\sin \theta_{M}+\cos \theta_{M}\right)$.
In the flat panel configuration, for $\theta_{\mathrm{M}} \leqslant 50^{\circ}$ type 3 has global advantages over the other ones, while for $\theta_{\mathrm{M}}>60^{\circ}$ the choice between the CPC and type 3 depends on the relative importance of space, mirror and insulation costs.

In the glass pipe configuration, for $\theta_{M} \leqslant 60^{\circ}$ type 4 has global advantages over type 2 , while this seems better for $\theta_{M}>60^{\circ}$.

\section{References}

[1] Winston, R., J. Opt. Soc. Am. 60 (1970) 245.

[2] Hinterberger, H. and Winston, R., Rev. Sci. Instrum. 37 (1966) 1094.

[3] Winston, R., Solar Energy 16 (1974) 89.

[4] BARANOV, V. K., Geliotekhnika 2 (1966) 11.

[5] BARANOV, V. K., Geliotekhnika 2 (1975) 36.

[6] Baranov, V. K., Opt. Mekahnic. Promyshlennost, 6 (1965).

[7] Winston, H. and Hinterberger, H., Solar Energy 17 (1975) 255.
[8] Patent by Trombe, F., Meinel, A. B. et al. presented by McKenney D. B. at the National Science Foundation Solar Thermal Review (March 1974).

Meinel, A. B. and Meinel, M. P., Applied Solar Energy : an introduction (Addison Wesley, Reading, Mass.) 1976.

[9] RABL, A., Solar Energy 18 (1976) 93.

[10] Mills, D. R. and GiUtronich, J. E., Solar Energy, 25 (1979) 85

[11] McIntiRe, W. R., Solar Energy 25 (1980) 215.

[12] Guay, E. J., Solar Energy 24 (1979) 265. 